\title{
Biologia reprodutiva de Psychotria spectabilis Steyrm. e Palicourea cf. virens (Poepp \& Endl.) Standl. (Rubiaceae) em uma floresta tropical úmida na região de Manaus, $\mathrm{AM}$, Brasil $^{1}$
}

\author{
Otilene dos Anjos Santos ${ }^{1,3,4}$, Antonio Carlos Webber² e Flávia Regina Capellotto Costa ${ }^{3}$
}

Recebido em 20/10/2006. Aceito em 4/06/2007

\begin{abstract}
RESUMO - (Biologia reprodutiva de Psychotria spectabilis Steyrm. e Palicourea cf. virens (Poepp. \& Endl.) Standl. (Rubiaceae) em uma floresta tropical úmida na região de Manaus, AM, Brasil). Este estudo descreve a fenologia reprodutiva, morfologia e biologia floral, polinização e sucesso reprodutivo de Psychotria spectabilis e Palicourea cf. virens. Psychotria spectabilis floresceu de setembro a dezembro enquanto Palicourea cf. virens floresceu de maio a outubro. As inflorescências de Psychotria spectabilis são inflorescências terminais do tipo capítulo, com brácteas amarelas, flores brancas e heterostilia associada a diferenças na papila estigmática. Palicourea cf. virens apresenta inflorescências terminais do tipo corimbo, com flores amarelas homostílicas. Os recursos florais oferecidos foram néctar e pólen em ambas as espécies. Os beija-flores Phaethornis bourcieri e o macho de Thalurania furcata foram os principais visitantes florais de Psychotria spectabilis. Palicourea cf. virens também foi visitada por Thalurania furcata, com maior freqüência de visitas pela fêmea desta espécie. A abelha Trigona fulviventris visitou as flores das duas espécies, mas se comportou como pilhadora. $\mathrm{O}$ sucesso reprodutivo pré-emergente (SRPE) das duas espécies foi baixo, embora tenham apresentado um alto potencial reprodutivo.
\end{abstract}

Palavras-chave: Biologia floral, Palicourea $\mathrm{cf}$. virens, Psychotria spectabilis, Rubiaceae

\begin{abstract}
Reproductive biology of Psychotria spectabilis Steyrm. and Palicourea cf. virens (Poepp. \& Endl.) Standl. (Rubiaceae) in a moist tropical forest at Manaus, Amazonas State, Brazil). This study describes the reproductive phenology, floral biology, pollination and reproductive success of Psychotria spectabilis and Palicourea cf. virens. Psychotria spectabilis flowered from September to December while $P$. cf. virens flowered from May to October. The terminal inflorescence of Psychotria spectabilis is of the capitate type with yellow bracts, white flowers and heterostyly associated with differences of stigmatic papillae. The terminal inflorescence of Palicourea cf. virens is a corymb with yellow, homostylous flowers. Flower resources include nectar and pollen for both species. The hummingbirds Phaethornis bourcieri and the male of Thalurania furcata were the main floral visitors of Psychotria spectabilis. Palicourea cf. virens was also visited by $T$. furcata, but the female was the main visitor. Trigona fulviventris visited flowers of both species, but was considered a thief. Pre-emergent reproductive success (PERS) of these two species was low, although they showed high reproductive potential.
\end{abstract}

Key words: Floral biology, Palicourea $\mathrm{cf}$. virens, Psychotria spectabilis, Rubiaceae

\section{Introdução}

A família Rubiaceae é bem representada no subbosque de florestas tropicais exercendo papel fundamental na estrutura da comunidade, além de ser fonte de recursos para os animais que se alimentam de pólen, néctar e frutos (Poulin et al. 1999; Castro \& Oliveira 2002; Melo et al. 2003). Seus representantes apresentam hábitos bastante variados como árvores, arbustos, lianas, ervas, epífitas e algumas raras espécies aquáticas (Gentry \& Emmons 1987) e um amplo espectro de polinizadores tais como borboletas e abelhas com probóscide longa (Stone 1996; Taylor 1997; Ortiz et al. 2000; Castro \& Oliveira 2002), mariposas (Imbert \& Richards 1993; Wolff et al. 2003), moscas (Riveros et al. 1995; Ortiz et al. 2000) e beija-flores (Bawa \& Beach 1983; Feinsinger \& Busby 1987; Passos \& Sazima 1995; Castro \& Oliveira 2001).

No Brasil, os estudos da biologia reprodutiva de Rubiaceae abordam tanto os aspectos gerais da fenologia, morfologia floral, sistema reprodutivo e interação com visitantes florais (Passos \& Sazima 1995; Machado \& Loiola 2000; Castro \& Oliveira 2001; 2002; Coelho \& Barbosa 2003; 2004; Castro \& Araújo

\footnotetext{
1 Parte da Dissertação de Mestrado do primeiro Autor

2 Universidade Federal do Amazonas, Instituto de Ciências Biológicas, Departamento de Biologia, Manaus AM (awebber@ufam.edu.br)

3 Coordenação de Pesquisa em Ecologia, Instituto Nacional de Pesquisa da Amazônia, Pós-graduação em Biologia Tropical e Recursos Naturais do Convênio INPA/UFAM (anfe@inpa.gov.br)

4 Autor para correspondência: otilene@inpa.gov.br
} 
2004) como apenas restringem-se a estudos de caso sobre a fenologia da família e os fatores bióticos e abióticos que influenciam seus padrões fenológiocos (Almeida \& Alves 2000; San Martin-Gajardo \& Morellato 2003). A grande maioria desses trabalhos está concentrada na região sudeste, e até o presente momento nenhum trabalho de biologia reprodutiva com representantes da família foi conduzido na Amazônia brasileira. Portanto, o objetivo deste trabalho é descrever a fenologia reprodutiva, a morfologia e a biologia floral, o sistema de polinização e avaliar o sucesso reprodutivo de Psychotria spectabilis e Palicourea cf. virens na região de Manaus/AM.

\section{Material e métodos}

Área de estudo - $\mathrm{O}$ estudo foi realizado em uma das áreas de mata contínua do Programa de Ecologia TEAM (Avaliação e Monitoramento de Florestas Tropicais - Convênio CI/INPA) (2²6'24''S $59^{\circ} 47^{\prime} 51^{\prime}$ 'W). Este projeto delimitou uma parcela de 100 hectares no $37 \mathrm{Km}$ da ZF - 3 dentro das áreas do Projeto Dinâmica Biológica de Fragmentos Florestais (PDBFF) localizada cerca de $80 \mathrm{~km}$ ao norte de Manaus, AM. Aárea de estudo é uma floresta ombrófila densa, típica de terra-firme, com altitude média variando entre 80 e $110 \mathrm{~m}$ acima do nível do mar e na classificação de Köppen o clima é tropical chuvoso do tipo quente e úmido (Alencar et al. 1979), com temperatura média anual de $26^{\circ} \mathrm{C}$. A precipitação anual varia entre 1.900 e $2.300 \mathrm{~mm}$.

Espécies estudadas - Psychotria spectabilis e Palicourea. cf. virens são frequentemente encontradas no sub-bosque de florestas tropicais úmidas do Amazonas. São arvoretas com cerca de 3,5 m de altura. Psyhotria spectabilis é encontrada principalmente nas áreas alagadas próximas aos igarapés, enquanto que Palicourea cf. virens encontra-se com maior frequiência nas áreas de platô.

Fenologia reprodutiva - Para o estudo da fenologia reprodutiva foi adotado o sistema de trilha (d'EçaNeves \& Morellato 2004) em uma área amostral de 1ha. Foram marcados dentro de um sistema de quatro trilhas (5 m larg. por $500 \mathrm{~m}$ compr.), 15 indivíduos adultos de cada espécie. O período de observação foi de novembro/2003 a dezembro/2004. As observações foram mensais, registrando-se a presença das fenofases de floração (dividida em botão e flores abertas) e frutificação (dividida em frutos imaturos e maduros). Os dados coletados para a sincronia das fenofases reprodutivas foram analisados por meio do método do Índice de Atividade, que consiste na constatação somente da presença ou ausência da fenofase no indivíduo, não estimando intensidade ou quantidade (Bencke \& Morellato 2002). Este método de análise permite quantificar a porcentagem de indivíduos da população que está manifestando determinado evento fenológico e também estima a sincronia entre os indivíduos de uma população. Dados pluviométricos foram fornecidos pelo setor de Climatologia do PDBFF durante o período de estudo.

Morfologia das inflorescências e flores - As inflorescências e as flores foram coletadas e fixadas em FAA (formalina-5 ml, ácido acético- $5 \mathrm{ml}$ e etanol$90 \mathrm{ml}$ ) para medir as seguintes estruturas: comprimento e diâmetro das inflorescências e flores, comprimento do estigma, comprimento do pistilo (desde a base do ovário até o ápice do estigma), altura dos estames (desde a base da corola até o ápice da antera) (Fig.1) Em Palicourea cf. virens foram coletadas 50 flores de 10 indivíduos, enquanto que em Psychotria spectabilis foram coletadas 30 flores por morfo, de um total de seis indivíduos longistilos e seis brevistilos.

Biologia floral - O horário de abertura e longevidade das flores foram definidos após marcação de 10 flores em pré-antese em cinco indivíduos de cada espécie, observados a partir das 2:30h até as 17:00h. O critério usado para a abertura da flor foi a separação das pétalas e da longevidade foi o escurecimento das estruturas reprodutivas e a queda das pétalas. A receptividade do estigma foi testada ao longo do dia por meio da atividade da peroxidase, utilizando-se água oxigenada a 3\% (Dafni 1992). Foi observada e avaliada neste período a liberação do pólen. Para a coleta do néctar foram utilizados microcapilares de $1 \mu \mathrm{l}, 2 \mu \mathrm{l}$, $3 \mu \mathrm{l}$. A medição do volume foi realizada em amostras do néctar acumulado (cerca de $12 \mathrm{~h}$ após a abertura da flor) nas flores em pré-antese previamente


Figura 1. Esquema da flor longistila e brevistila em corte longitudinal (extraído de Coelho \& Barbosa 2004). 
ensacadas com sacos de papel, evitando-se desta maneira, a interferência dos visitantes. O procedimento utilizado para a coleta do néctar objetivando a medição da porcentagem de açúcares dissolvidos, foi o mesmo adotado para o cálculo do volume, transferindo-se diretamente as amostras dos microcapilares para um refratômetro manual Modelo REF 107 (Kearns \& Inouye 1993). A presença de células liberadoras de odor foi testada durante o período de antese com o vermelho neutro usando 10 flores para cada espécie (Dafni 1992).

Visitantes e potenciais polinizadores - O comportamento dos visitantes foi estudado por observações visuais diretas ou com o auxílio de binóculos, em horários variados do dia em cinco indivíduos de cada espécie, e complementado pela análise de fotografias obtidas em campo. As observações ocorreram entre os meses de julho a novembro/2004. O estudo do comportamento dos visitantes e potenciais polinizadores seguiu os procedimentos descritos por Ramirez \& Brito (1992). Os visitantes foram classificados de acordo com a freqüência das visitas como raros, comuns e muito comuns. A observação dos visitantes de Palicourea cf. virens ocorreu entre os meses de agosto e setembro/2004, entre 6:00 e 16:00h, com um total de 60 horas. Os visitantes de Psychotria spectabilis foram observados entre 6:00 e 15:00h, entre os meses de setembro a novembro, com um total de $78 \mathrm{~h}$ de observações.

Coleta e identificação - As exsicatas das espécies estudadas estão depositadas no herbário do INPA (213859 e 215615). Os insetos coletados foram incluídos na coleção entomológica do INPA e identificados por especialistas. Para as aves, a identificação foi feita por especialista a partir de registros fotográficos.

Sucesso reprodutivo - Para quantificar o potencial e o sucesso reprodutivo em condições naturais, foram selecionados cinco indivíduos de cada espécie. A metade das inflorescências produzidas por indivíduo foi selecionada para a contagem do número de botões em cada inflorescência. Depois foi contado o número de flores abertas por inflorescência, assim como o número de frutos formados. O número de sementes por fruto foi determinado pela sua dissecação. As inflorescências nas quais foi observada a formação de fruto foram ensacadas para evitar predação e, assim, poder contar o número de sementes. O sucesso reprodutivo pré-emergente (SRPE) (Wiens et al. 1987) foi calculado pela razão de frutos por flor (Fruto/Flor) multiplicado pela razão de sementes por óvulos (Sementes/Óvulos).

Análise estatística - As medições das estruturas florais entre os diferentes morfos de Psychotria spectabilis foram comparadas usando o teste " $t$ " de Student por meio do programa estatístico MINITAB. As medidas das estruturas florais e da concentração e volume do néctar foram feitas por meio de médias e desvio padrão respectivamente.

\section{Resultados}

Fenologia reprodutiva - As Fig. 2-3 mostram as fenofases de floração e frutificação de Palicourea cf. virens e Psychotria spectabilis respectivamente. A floração de Palicourea $\mathrm{cf}$. virens ocorreu no final do período de chuvas, entre maio e outubro/2004. A maior porcentagem de indivíduos florindo (86\%) ocorreu no mês de agosto/2004, sendo altamente sincrônico nesse período. No mês de novembro/2003 também foram observados indivíduos florindo. Não houve sincronia na frutificação de Palicourea cf. virens, mas o maior número de indivíduos frutificando ocorreu entre os meses de novembro/2003 e março/2004 e outros no meio e final da estação seca (agosto a outubro/2004). A floração de Psychotria spectabilis ocorreu entre o final da época seca e início da chuvosa, com maior sincronia $(80 \%)$ entre os indivíduos nos meses de novembro/2003 e dezembro/2004. Quanto à frutificação de Psychotria spectabilis, ocorreu nos meses de dezembro/2003 a maio/2004 e em dezembro/2004, com maior sincronia (80\%) nos meses de dezembro de 2003 e 2004.

Morfologia das inflorescências e flores - As flores de Palicourea cf. virens estão dispostas em inflorescências do tipo corimbo, com uma média de 49 (2-135) flores por inflorescência $(n=30)$, emitida entre dois pares de folhas. As inflorescências tiveram em média 7, $83 \pm 1,95 \mathrm{~cm}$ de comprimento e 7,07 $\pm 1,66 \mathrm{~cm}$ de diâmetro e os pedúnculos 3,79 $\pm 1,18 \mathrm{~cm}$ de comprimento $(\mathrm{n}=30)$. As flores são subsésseis, hermafroditas, actinomorfas e isostêmones. A corola é amarela, gamopétala, pentâmera, formando um tubo de consistência rígida com comprimento médio de $2,09 \pm 0,18 \mathrm{~cm}(\mathrm{n}=50)$ e abertura média de $4,34 \pm 0,85 \mathrm{~mm}(\mathrm{n}=50)$ (Fig. 4a). Na região média basal do tubo da corola há um anel de tricomas longos que fecham e protegem a câmera nectarífera. O nectário é epígino, lobado e em forma de colar localizado na base do tubo da corola. 
278 Santos, Webber \& Costa: Biologia reprodutiva de Psychotria spectabilis Steyrm. e Palicourea cf. virens (Poepp. ...

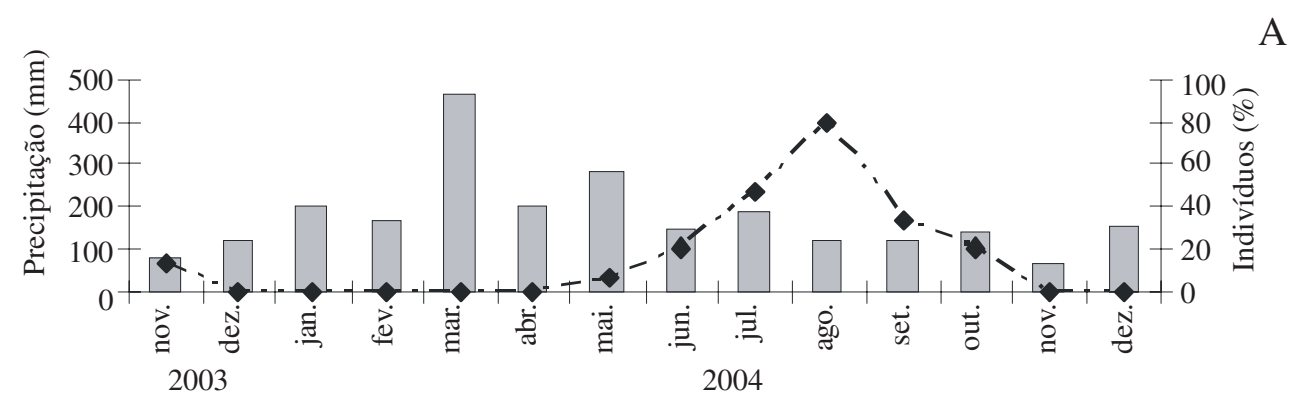

A

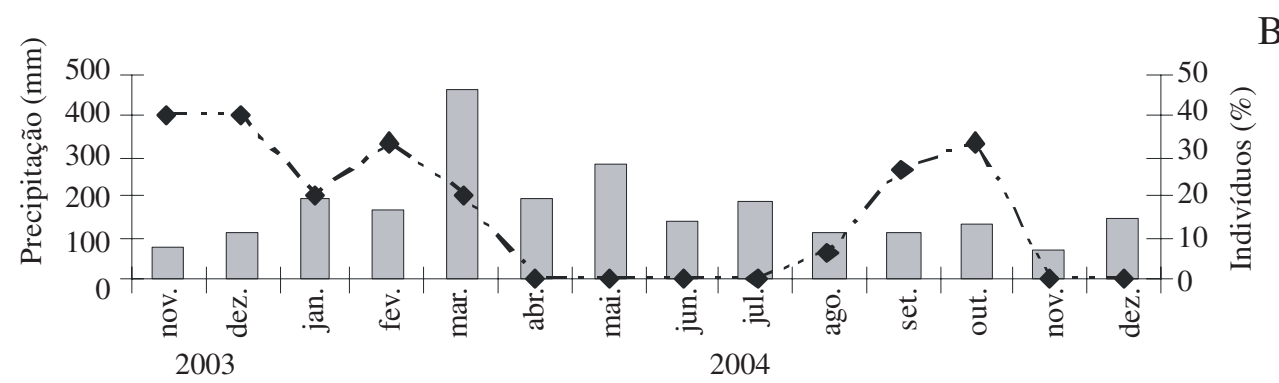

Figura 2. Porcentagem de indivíduos em floração (A) e frutificação (B) para Palicourea cf. virens de novembro/2003 a dezembro/2004. ( $=$ precipitação).
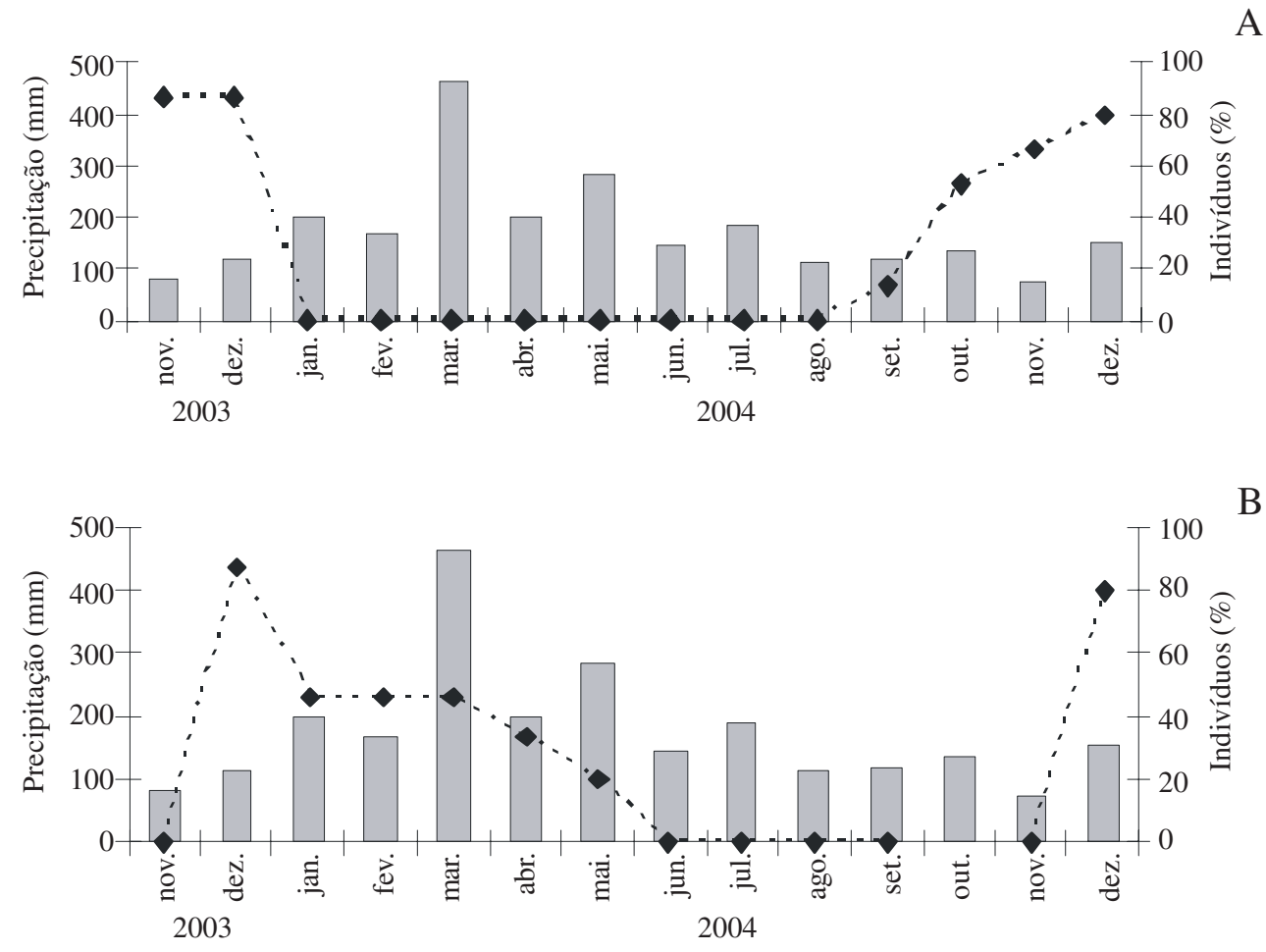

Figura 3. Porcentagem de indivíduos em floração (A) e frutificação (B) para Psychotria spectabilis de novembro/2003 a dezembro/2004. ( = precipitação). 
$\mathrm{O}$ androceu é composto por cinco estames férteis, dialistêmones, epipétalos. Os filetes e as anteras são glabros, amarelados, fundidos até a porção mediana com o tubo da corola e alternipétalos. As anteras possuem deiscência longitudinal, são dorsifixas, bitecas, com média de $4 \mathrm{~mm}(\mathrm{n}=40)$ sem variação no comprimento. O comprimento médio das anteras é de $1,6 \pm 0,07 \mathrm{~cm}(\mathrm{n}=60)$. O pistilo tem em média $1,52 \pm 0,08 \mathrm{~cm}$ de comprimento $(\mathrm{n}=50)$, possui ovário ínfero, pentacarpelar, pentalocular com um óvulo em cada lóculo. O estigma é bífido e os lacínios ficam úmidos quando receptivos. Todos os indivíduos da população estudada mostraram anteras e estigma no mesmo nível dentro da flor, evidenciando homostilia (Fig. 4b).

Em Psychotria spectabilis, as flores estão dispostas em inflorescências do tipo capítulo, compostas por oito brácteas amarelas, com média de 8 (5-11) flores por inflorescência $(n=30)$, emitida entre um par de folhas. As inflorescências têm em média $3,81 \pm 0,36 \mathrm{~cm}$ de comprimento $(\mathrm{n}=30)$ e $6,16 \pm 0,69 \mathrm{~cm}$ de diâmetro $(n=30)$. As flores são sésseis, hermafroditas, actinomorfas e isostêmones. O cálice é densamente piloso na face externa de cor creme amarelado. A corola branca é também densamente pilosa na face externa, gamopétala e pentâmera (Fig. 4d). Na região média basal da corola há um anel de pêlos longos que fecham e protegem a câmara nectarífera. O nectário é epígino, lobado e em forma de colar localizado na base do tubo da corola. $O$ androceu é composto por cinco estames férteis, dialistêmones, epipétalos em ambos os morfos. Os filetes e as anteras são glabros, brancos e alternipétalos. As anteras são dorsifixas, bitecas com deiscência longitudinal. O gineceu possui ovário ínfero, bilocular com um óvulo em cada lóculo.

A população de Psychotria spectabilis observada apresentou dois tipos florais: flores brevistilas e longistilas. Os dois morfos diferem quanto à posição das anteras $(\mathrm{t}=-31,74, \mathrm{p}<0,001)$, comprimento do pistilo $(\mathrm{t}=36,77, \mathrm{p}<0,001)$ e comprimento do estigma $(\mathrm{t}=-18,65, \mathrm{p}<0,001)$, (Tab. 1). Não houve diferença significativa no comprimento $(\mathrm{t}=-1,03, \mathrm{p}=0,31)$ ou no diâmetro $(\mathrm{t}=-1,02, \mathrm{p}=0,31)$ da corola entre os dois morfos (Fig. 4e).

Biologia floral - A abertura das flores de Palicourea cf. virens ocorreu a partir das 4:30h, estando a flor completamente aberta em torno das 7:00h. O estigma tornou-se receptivo logo após a abertura da flor por

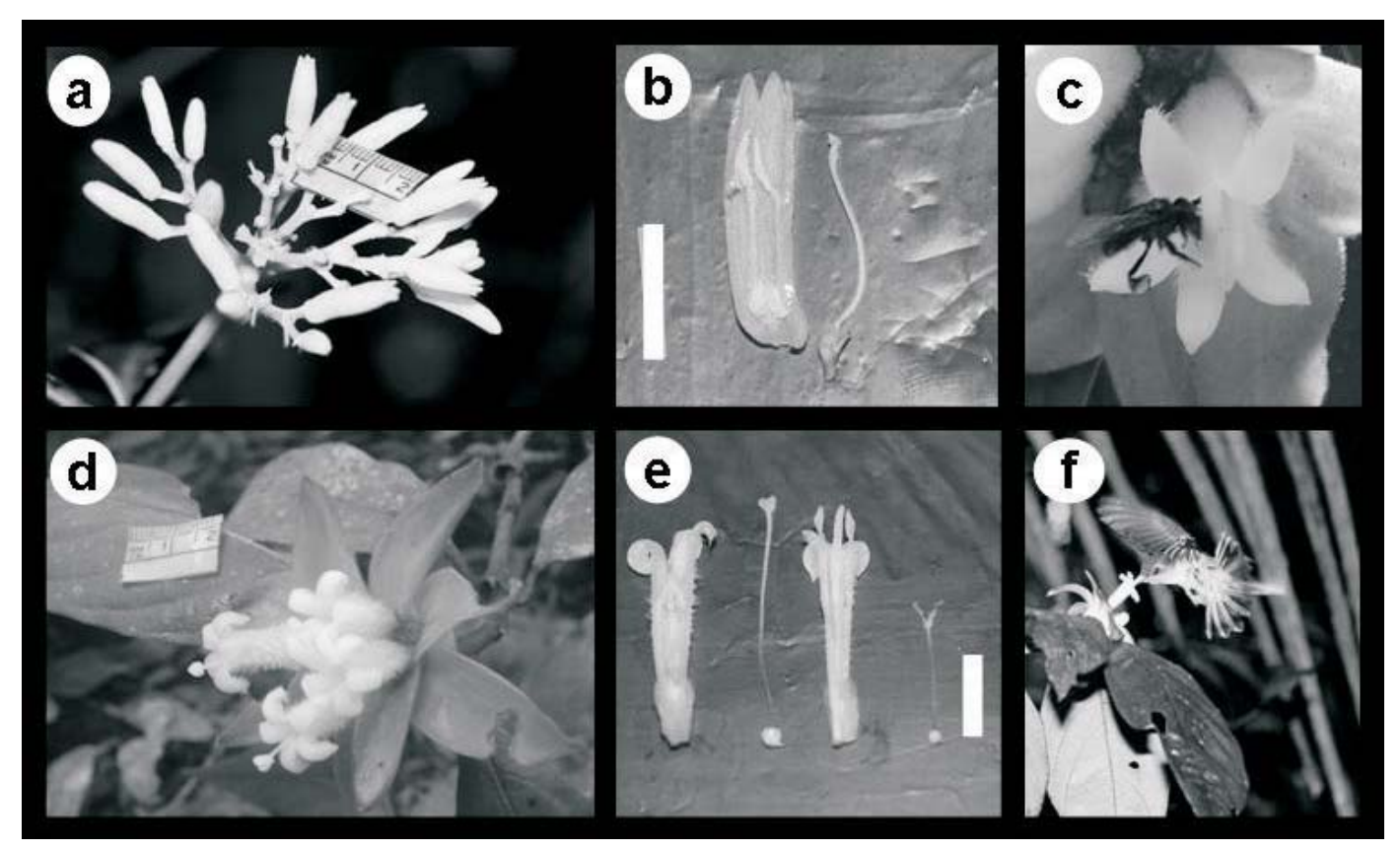

Figura 4. Inflorescências, flores e visistantes de Palicourea cf. virens (Poepp. \& Endl) Standl e de Psychotria spectabilis Steyrm. a. Inflorescência de Palicourea cf. virens. b. Detalhe da flor de $P$. cf. virens mostrando a posição das anteras e do estigma $(B a r r a=1 \mathrm{~cm})$; c. A abelha Trigona fulviventris coletando pólen das flores brevistilas de Psychotria spectabilis. d. Inflorescência longistila de Psychotria spectabilis. e. Detalhe dos morfos de Psychotria spectabilis $(1 \mathrm{~cm})$. A esquerda flor longistila e a direita flor brevistila. f. O beija-flor Phaethornis bourcieri visitando as flores longistilas de Psychotria spectabilis. 
Tabela 1. Dimensões florais (média \pm desvio-padrão) dos morfos brevistilos e longistilos de Psychotria spectabilis.

\begin{tabular}{lcc}
\hline \multirow{2}{*}{ Características florais } & \multicolumn{2}{c}{ Morfos } \\
\cline { 2 - 3 } & $\begin{array}{c}\text { Brevistila } \\
(\mathrm{n}=30)\end{array}$ & $\begin{array}{c}\text { Longistila } \\
(\mathrm{n}=30)\end{array}$ \\
\hline Comprimento da flor $(\mathrm{cm})$ & $3,22 \pm 0,09$ & $3,16 \pm 0,30$ \\
Diâmetro da flor $(\mathrm{cm})$ & $1,13 \pm 0,14$ & $1,09 \pm 0,13$ \\
${\text { Comprimento do estigma }(\mathrm{mm})^{\mathrm{a}}}^{\mathrm{a}}$ & $4,83 \pm 0,79$ & $1,73 \pm 0,45$ \\
${\text { Comprimento do pistilo }(\mathrm{cm})^{\mathrm{a}}}$ & $1,38 \pm 0,09$ & $3,03 \pm 0,22$ \\
Altura do estame $(\mathrm{cm})^{\mathrm{a}}$ & $3,22 \pm 0,10$ & $2,25 \pm 0,12$ \\
\hline
\end{tabular}

${ }^{a}$ Diferenças altamente significativas $(\mathrm{p}<0,001)$.

volta de 5:30h, e as anteras começaram a liberação do pólen pouco depois. As flores de Palicourea cf. virens tiveram apenas um dia de duração. As flores abertas permaneceram com uma consistência firme até por volta das 16:00h, quando a corola começou perder a sua turgidez e murchar. Neste mesmo período, as anteras começaram a escurecer (coloração amarronzada). Vinte e quatro horas depois da abertura da flor, o cálice, a corola e o estilete caíram, permanecendo apenas o ovário e o disco nectarífero. Não foi detectado odor nas flores. A produção de néctar teve volume médio por flor de $5,0 \pm 4,2 \mu \mathrm{l}$ e porcentagem média de $20 \pm 3,8 \%$ $(\mathrm{n}=20)$.

Em Psychotria spectabilis a abertura das flores iniciou-se entre 3:00h e 4:00h, e cerca de duas horas após esse período todas as flores do indivíduo já estavam completamente abertas. O estigma tornou-se receptivo por volta de 6:00h e a liberação de pólen ocorreu por volta das 7:00h. O teste de peroxidase, feito de duas em duas horas desde a abertura da flor até o final da tarde (16:00h), mostrou que o estigma apresenta maior receptividade entre 9:00 e 11:00h e continua receptivo até 14:00h. A duração da flor foi de um dia. Durante o período da manhã, as flores apresentaram coloração branca, mas $12 \mathrm{~h}$ após a abertura da flor os lobos da corola ficaram amarelados e as anteras amarronzadas. No dia seguinte à abertura, a corola e o estilete haviam caído, permanecendo apenas o cálice, o ovário e o disco nectarífero. Não foi detectado odor nas flores. A média do volume e da porcentagem do néctar foi de $10,0 \pm 6,10 \mu \mathrm{l}$ e $21 \pm 2,14 \%$ respectivamente para as flores longistilas $(\mathrm{n}=15)$ e $12,0 \pm 3,95 \mu \mathrm{l}$ e $23 \pm 5,67 \%$ respectivamente para as flores brevistilas $(\mathrm{n}=15)$.

Visitantes - Os visitantes de Palicourea cf. virens foram uma espécie de beija-flor, uma espécie de abelha e algumas espécies de borboletas $(<5)$, as quais não foi possível registrar a quantidade exata. O beija-flor Thalurania furcata foi o principal visitante floral dessa espécie (Tab. 2). Suas visitas iniciavam-se por volta das 6:00h, sendo mais intensas entre 8:00 e 10:00h e prolongando-se até o final da manhã, havendo poucas visitas no período da tarde. A fêmea dessa espécie foi o visitante mais freqüente, mas o macho também visitou as flores de Palicourea cf. virens. Todas as flores abertas no dia eram visitadas, mesmo aquelas dispostas a poucos centímetros do chão. Durante as visitas, Thalurania furcata tocava com o bico as anteras e o estigma das flores.

Palicourea cf. virens também foi visitada pela abelha Trigona fulviventris (Tribo - Meliponini) que começou a coleta de pólen e néctar por volta das 7:45h. Essa espécie comportou-se como pilhadora, pois, além de permanecer muito tempo no mesmo indivíduo, na maior parte do tempo perfurava a base da corola em busca de néctar. O restante do tempo coletava pólen. Ao pousar na flor, Trigona fulviventris introduzia a cabeça na entrada da corola tocando nas anteras e estigma simultaneamente, visto que as estruturas reprodutivas encontravam-se dispostas no mesmo nível dentro da flor, podendo talvez ser uma polinizadora ocasional desta espécie. Poucas espécies de borboletas visitaram as flores de Palicourea $\mathrm{cf}$. virens, sendo identificada apenas Adelotype sp1 (macho).

Os visitantes registrados para Psychotria spectabilis foram duas espécies de abelhas e duas espécies de beija-flor. As primeiras visitas foram feitas pelo beija-flor Phaethornis bourcieri a partir das 7:00h, prolongando-se até o final da tarde, por volta de 16:00h (Fig. 4f). Essa espécie de beija-flor foi o

Tabela 2. Visitantes florais de Palicourea cf. virens e Psychotria spectabilis e a freqüência de suas visitas. *Segundo Ramirez \& Brito (1992) ver Material e métodos.

\begin{tabular}{lc}
\hline Espécies & $\begin{array}{c}\text { Classificação } \\
\text { das visitas* }\end{array}$ \\
\hline Palicourea cf. virens & \\
Adelotype sp1. (macho) & raras \\
Trigona fulviventris Guérin, 1835 & muito comuns \\
Thalurania furcata (Gmelin,1788) (fêmea) & muito comuns \\
Thalurania furcata (Gmelin,1788) (macho) & comuns \\
Psychotria spectabilis & \\
Trigona fulviventris Guérin, 1835 & comuns \\
Plebéia minima (Gribodo, 1893) & raras \\
Thalurania furcata $($ Gmelin,1788) (macho) & comuns \\
Phaethornis bourcieri & muito comuns
\end{tabular}


visitante mais freqüente e responsável pelas visitas legítimas nos dois tipos florais (Tab. 2). Suas visitas foram mais intensas entre 7:00 e 11:00h. O macho de Thalurania furcata também visitou as flores de Psychotria spectabilis, mas com menor freqüência. Durante as visitas às flores, os beija-flores inseriram o bico no tubo floral, mantendo contato primeiro com as anteras e depois com o estigma nas flores brevistilas, enquanto em flores longistilas o processo foi inverso. Os beija-flores visitavam todas as flores em antese no mesmo indivíduo e em indivíduos mais próximos.

As duas espécies de abelhas observadas visitando as flores de Psychotria spectabilis foram Trigona fulviventris (Fig. 4c) e Plebeia minima. Trigona fulviventris foi o visitante mais freqüente, mas coletou pólen somente nas flores brevistilas, que possuem os estames inseridos na parte superior da corola. Nas flores longistilas, Trigona fulviventris não conseguia alcançar as anteras para coletar pólen, sendo raras as visitas nesse morfotipo. Plebeia minima teve o mesmo comportamento de Trigona fulviventris, conseguindo coletar pólen e tocar no estigma das flores brevistilas e por ser menor, conseguia entrar nas flores longistilas para coletar pólen. Elas foram consideradas pilhadoras, pois passavam muito tempo em um mesmo indivíduo coletando pólen, tocando raramente os estigmas. As visitas de ambas espécies de abelha foram mais freqüentes entre 8:00 e 10:00h.

Sucesso reprodutivo - O potencial reprodutivo e o sucesso reprodutivo pré-emergente (SRPE) das espécies estão sumarizados na Tab. 3. Para Palicourea cf. virens, o número de flores abertas foi de $89 \%$, enquanto que a razão de frutos por flores foi de $68 \%$ de frutos que sobreviveram até o estágio maduro. Foram observados cinco óvulos por flor, com o SRPE de 44\%. O número de flores abertas foi de $89 \%$ para as flores brevistilas e de $92 \%$ para as flores longistilas de Psychotria spectabilis. A razão de frutos formados por flores foi de $46 \%$ e de $36 \%$ para as flores brevistilas e longistilas respectivamente. O SRPE foi baixo para os dois morfos de Psychotria spectabilis, sendo $7 \%$ para as flores brevistilas e $4 \%$ para as longistilas.

\section{Discussão}

A floração e frutificação de Psychotria spectabilis e Palicourea cf. virens mostraram um padrão anual, embora o curto período de observação deste estudo (13 meses) seja um claro limite a esta interpretação. Quanto à sazonalidade, as duas espécies floresceram em épocas diferentes do ano, tendo Psychotria spectabilis florescido no período chuvoso e Palicourea cf. virens no período seco. Os estudos fenológicos realizados com outras espécies da família mostram que a sazonalidade é bastante divergente para as espécies arbustivas, com trabalhos mostrando padrões sazonais (Castro \& Oliveira 2002) e outros não-sazonais (Opler et al. 1980; Koptur et al. 1988; Almeida \& Alves 2000; San Martin-Gajardo \& Morellato 2003).

Para as espécies arbóreas de Rubiaceae, no entanto, a floração é caracterizada por apresentar um padrão sazonal, pelo menos para a comunidade da floresta Atlântica (Morellato et al. 2000). Diferenças no período de floração entre espécies de dossel e subbosque têm sido registradas em algumas comunidades de floresta tropical (Frankie et al. 1974; Alencar et al . 1979; Opler et al. 1980). Entretanto, variações no comportamento fenológico de espécies de uma mesma família encontradas em diferentes posições estratigráficas numa mesma área de floresta foi registrado somente por San Martin-Gajardo \& Morellato (2003). De acordo com esses autores, essas

Tabela 3. Sucesso reprodutivo pré-emergente de Palicourea cf. virens e Psychotria spectabilis.

\begin{tabular}{|c|c|c|c|}
\hline \multirow[t]{2}{*}{ Características florais } & \multirow[t]{2}{*}{$P$. cf. virens } & \multicolumn{2}{|c|}{ P. spectabilis } \\
\hline & & Brevistila & Longistila \\
\hline Número de botões & 1215 & 87 & 193 \\
\hline Número de flores abertas & 1097 & 78 & 178 \\
\hline Porcentagem de sobrevivência (\%) & 89,8 & 89,6 & 92,2 \\
\hline Número frutos formados por flores & 755 & 36 & 119 \\
\hline Número de sementes formadas por frutos & 3609 & 64 & 189 \\
\hline Razão de frutos por flores & 0,68 & 0,46 & 0,36 \\
\hline Razão de sementes por óvulo & 0,65 & 0,16 & 0,13 \\
\hline Sucesso reprodutivo pré-emergente & 0,44 & 0,073 & 0,046 \\
\hline
\end{tabular}


diferenças podem estar relacionadas com o habitat (diferenças microclimáticas) e com o hábito arbustivo predominante nas plantas do sub-bosque.

Embora as duas espécies tenham florescido ao longo do ano, não houve coincidência no pico de floração entre elas. A separação temporal da floração entre as espécies pode estar servindo como mecanismo de isolamento na especiação, estabelecendo e mantendo a divergência sobre o período de floração como ocorre nas espécies simpátricas (Gentry 1974; Stiles 1975; Campbell 1985; Gottsberger 1986; Newstrom et al. 1994).

As flores de Psychotria spectabilis são brancas, mas a inflorescência possui um conjunto de brácteas de cor alaranjado intenso que servem como atrativo visual, assim como a coloração amarelada das inflorescências e das flores de Palicourea cf. virens. Essas características associadas à sincronia de floração observada entre os indivíduos das duas espécies podem estimular o deslocamento dos beijaflores entre as plantas co-específicas e exercer um papel importante na atração deles, pois esses animais enxergam cores desse espectro, aumentando as chances de polinização cruzada (Stiles 1975).

A população de Psychotria spectabilis apresentou heterostilia associada a diferenças no comprimento dos estigmas. A heterostilia é bastante comum nos representantes estudados da família Rubiaceae, principalmente no gênero Psychotria (Hamilton 1990; Faivre \& McDade 2001; Lau \& Bosque 2003; Castro \& Araújo 2004). Psychotria spectabilis apresentou diferenças na fecundidade entre os morfos florais, sendo esta maior nas flores brevistilas.

De acordo com Ree (1997) a heterostilia associada às diferenças na superfície estigmática pode influenciar o fluxo de pólen entre os morfos, e no caso das espécies que apresentam as flores brevistilas com superfície estigmática maior do que flores longistilas, essa diferença pode estar compensando a deposição desigual do pólen. Nos estudos de Levin (1968), Ornduff (1970) e Weller (1980) a deposição de pólen foi maior nas flores longistilas que apresentaram estigmas mais compridos em relação aos estigmas das flores brevistilas. No entanto, em Psychotria spectabilis, Palicourea padiflora (Ree 1997) e Palicourea fendleri (Lau \& Bosque 2003) as flores brevistilas apresentaram estigmas mais compridos comparados às flores longistilas. Diferença no tamanho do estigma talvez seja mais importante na diferença do fluxo de pólen do que a posição do estigma. A maior parte das espécies heterostílicas é adaptada à polinização por animais de língua comprida e comumente possuem flores actinomorfas, tubulares com hercogamia recíproca (Lloyd \& Webb 1992a; b).

O comportamento do polinizador também pode influenciar no padrão de deposição do pólen. De acordo com Coelho \& Barbosa (2004), os polinizadores que visitaram indistintamente os diferentes morfos de Psychotria poeppigiana permitiram um fluxo de pólen simétrico, com igual proporção de frutos formados entre os morfos. Isso pode ter ocorrido também devido ao dimorfismo no comprimento do estilete, onde as flores brevistilas apresentaram estigmas bem maiores do que as longistilas.

Ao contrário de Psychotria spectabilis, a população de Palicourea cf. virens apresentou flores homostílicas, embora pertença a um gênero quase exclusivamente distílico (Taylor 1997). A homostilia no gênero Palicourea foi citada apenas para duas espécies, Palicourea alpina (Tanner 1982) e Palicourea macrobotrys (Coelho \& Barbosa 2003), não sendo, portanto, muito comum para o gênero. Todavia, a homostilia ainda não pode ser reconhecida para a espécie Palicourea cf. virens, como observado por Coelho \& Barbosa (2003) com Palicourea macrobotrys, pois somente uma população foi observada, sendo necessárias observações em outras regiões com outras populações, para determinar se essa característica é comum na espécie como um todo, ou apenas em populações isoladas. Richards (1986) sugere que a homostilia está associada com a perda da incompatibilidade.

Os beija-flores que visitaram Psychotria spectabilis e Palicourea cf. virens pareciam seguir linhas de captura, não mostrando territorialidade (Sazima et al. 1996) durante as visitas. Esse tipo de comportamento pode auxiliar num maior fluxo de pólen entre os indivíduos e, conseqüentemente, maior sucesso reprodutivo (Coelho \& Barbosa 2003). Apesar das características ornitófilas, as flores de Psychotria spectabilis também foram visitadas por abelhas e borboletas, porém com menor freqüência. Em Psychotria spectabilis, a abelha Trigona fulviventris foi considerada pilhadora, pois somente coletava pólen nas flores brevistilas, o que era facilitado pelo posicionamento das anteras no ápice da corola.

O volume e a porcentagem de néctar em Psychotria spectabilis e Palicourea cf. virens embora tenham sido baixos, estão de acordo com o encontrado para espécies ornitófilas (Sazima et al. 1996; Buzato et al. 2000; Leal et al. 2006). Essa baixa 
produção de néctar registrada pode representar uma estratégia para que os animais precisem visitar flores de outros indivíduos em busca de mais recursos gerando com isso, um grande movimento entre os indivíduos da mesma espécie e promovendo a polinização cruzada, principalmente para as espécies que apresentam heterostilia, como é o caso de Psychotria spectabilis. Tanto Psychotria spectabilis como Palicourea cf. virens apresentaram alta sincronia e um grande número de flores abertas por indivíduo e entre os indivíduos, tornando assim alto o volume de néctar na população durante o pico de floração nas plantas observadas.

Os atributos florais, tais como flores tubulosas de coloração conspícua, parede da corola espessa, presença de pêlos protetores internos que evitam a pilhagem de néctar por insetos pequenos, produção de néctar e ausência de odor indicam que as espécies Psychotria spectabilis e Palicourea cf. virens podem ser enquadradas na síndrome de ornitofilia descrita por Faegri e van der Pijl (1979). A posição terminal das inflorescências, bem como a disposição lateralmente inclinada da maioria das flores de ambas as espécies, facilitam o acesso e a retirada de néctar por beija-flores, que possuem o hábito de pairar durante a visita (Stiles 1975).

O sucesso reprodutivo pré-emergente (SRPE) de Palicourea cf. virens foi alto, enquanto que para Psychotria spectabilis o SRPE foi baixo. De acordo com Bawa (1990), em muitas espécies de plantas nem todos os óvulos se tornam semente, muitas vezes influenciado pelo número de grãos de pólen depositados no estigma. Outra causa seria a competição por recursos onde as flores que abrem primeiro têm maior probabilidade de retenção do que aquelas que abrem mais tarde (Bawa \& Webb 1984).

Os dados sobre a biologia reprodutiva registrados para Palicourea cf. virens e Psychotria spectabilis não diferem muito dos encontrados em outras espécies da família Rubiaceae nas diferentes regiões do Brasil e em outras florestas tropicais. Por outro lado, isso representa apenas uma ínfima parte da grande diversidade da floresta amazônica principalmente para a família Rubiaceae, um dos maiores representantes do sub-bosque de matas tropicais.

\section{Agradecimentos}

À Dra. Catarina Motta, pela identificação da espécie de borboleta; ao Dr. Mario Eric Cohn-Haft, pela identificação dos beija-flores; ao Dr. Marcio Luiz de Oliveira, pela identificação das abelhas; ao CNPq, pela concessão de bolsa para a primeira autora e financiamento do projeto "Biologia reprodutiva de espécies de sub-bosque”, processo n. 47064/2003-3. Agradecemos ao Projeto Dinâmica Biológica de Fragmentos Florestais (PDBFF) pelo apoio logístico e financeiro.

\section{Referências bibliográficas}

Alencar, J.C.; Almeida, R.A. \& Fernandes, N.P. 1979. Fenologia de espécies florestais em floresta tropical úmida de terra firme na Amazônia Central. Acta Amazonica 9: 163-198.

Almeida, E.M. \& Alves, M.A. 2000. Fenologia de Psychotria $n u d a$ e $P$. brasiliensis (Rubiaceae) em uma área de Floresta Atlântica no sudeste do Brasil. Acta Botanica Brasilica 14: 335-346.

Bawa, K.S. \& Webb, C.J. 1984. Flower, fruit and seed abortion in tropical tree: Implications for evolution of paternal and maternal reproduction patterns. American Journal of Botany 71: 736-751.

Bawa, K.S. 1990. Plant-pollinator interactions, sexual systems and pollen flow-comentary. Pp.17-20. In: K.S. Bawa \& M. Hadley (eds.). Reproductive ecology of tropical forest plants. Paris, UNESCO.

Bawa, K.S. \& Beach, J.H. 1983. Self-incompatibility systems in the Rubiaceae of a tropical lowland wet forest. American Journal of Botany 70: 1281-1288.

Bencke, C.S.C. \& Morellato, P.C. 2002. Comparação de dois métodos de avaliação da fenologia de plantas, sua interpretação e representação. Revista Brasileira de Botânica 25: 269-275.

Buzato, S.; Sazima, M. \& Sazima, I. 2000. Hummingbirdpollinated floras at three Atlantic forest sites. Biotropica 32: 824-841.

Campbell, D.R. 1985. Pollinator sharing and seed set of Stellaria pubera: competition for pollination. Ecology 66: $544-553$.

Castro, C.C. \& Araújo, A.C. 2004. Distyly and sequencial pollinators of Psychotria nuda (Rubiaceae) in the Atlantic rain forest, Brazil. Plant Systematics and Evolution 244: 131-134.

Castro, C.C. \& Oliveira, P.E. 2001. Reproductive biology of the protandrous Ferdinandusa speciosa Pohl. (Rubiaceae) in southeastern SE Brazil. Revista Brasileira de Botânica 24: 167-172.

Castro, C.C. \& Oliveira, P.E. 2002. Pollination biology of distilous Rubiaceae in the Atlantic Rain Forest, SE Brazil. Plant Biology 4: 640-646.

Coelho, C.P. \& Barbosa, A.A.A. 2003. Biologia reprodutiva de Palicourea macrobotrys Ruiz \& Pavon (Rubiaceae): um possível caso de homostilia no gênero Palicourea Aubl. Revista Brasileira de Botânica 26: 403-413.

Coelho, C.P. \& Barbosa, A.A.A. 2004. Biologia reprodutiva de Psychotria poeppigiana Muell. Arg. (Rubiaceae) em mata de galeria. Acta Botanica Brasilica 18: 481-489. 
Dafni, A. 1992. Pollination ecology: a practical approach. New York, Oxford University Press.

d'Eça-Neves, F.F. \& Morellato, L.P. 2004. Método de amostragem e avaliação utilizados em estudos fenológicos de florestas tropicais. Acta Botanica Brasilica 18: 99-118.

Faegri, K. \& van der Pijl. L. 1979. The principles of pollination ecology. New York, Oxford, Pergamon Press.

Faivre, A.M. \& McDade, L.A. 2001. Population-level variation in the expression of heterostyly in three species of Rubiaceae: does reciprocal placement of anthers and stigmas characterize heterostyly? American Journal of Botany 88: 841-853.

Feinsinger, P. \& Bubsy, W.H. 1987. Pollen carryover: experimental comparisons between morphs of Palicourea lasiorrachis (Rubiaceae) a distylous, birdpollinated, tropical treelet. Oecologia 73: 231-235.

Frankie, G.W.; Baker, H.G. \& Opler, P.A. 1974. Comparative phonological studies of trees in tropical wet and dry forest in the lowland of Costa Rica. Journal of Ecology 62: 881-919.

Gentry, A.H. 1974. Flowering phenology and diversity in tropical Bignoniaceae. Biotropica 6: 64-68.

Gentry, A.H. \& Emmons, H.L. 1987. Geographical variation in fertility, phenology, and composition of the understory of neotropical forest. Biotropica 19: 216-227.

Gottsberger, G. 1986. Some pollination strategies in neotropical savannas and forests. Plant Systematic and Evolution 152: 30-45.

Hamilton, C.W. 1990. Variation on a distylous theme in a Mesoamerican Psychotria subgenus Psychotria (Rubiaceae). Memoirs of the New York Botanical Garden 55: 62-75.

Imbert, F.M. \& Richards, J.H. 1993. Protandry, incompatibility, and secondary pollen presentation in Cephalanthus occidentalis (Rubiaceae). American Journal of Botany 80: 395-404

Kearns, C.A. \& Inouye, D.W. 1993. Techniques for pollination biologists. Colorado, University Press of Colorado.

Lau, P. \& Bosque C. 2003. Pollen flow in the distylous Palicourea fendleri (Rubiaceae): an experimental test of the disassortative pollen flow hypothesis. Oecologia 15: 593-600.

Leal, C.F.; Lopes, V.A. \& Machado, C.I. 2006. Polinização por beija-flores em uma área de caatinga no Município de Floresta, Pernambuco, Nordeste do Brasil. Revista Brasileira de Botânica 29: 379-389.

Levin, D.A. 1968. The breeding system of Lithospermum carolinense: adaptation and counter adaptation. American Naturalist 102: 427-441.

Lloyd, D.G. \& Webb, C.J. 1992a. The evolution of heterostyly. Pp.151-178. In: S.C.H. Barrett (ed.). Evolution and function of heterostyly. Springer-Verlag, Berlin.

Lloyd, D.G. \& Webb, C.J. 1992b. The selection of heterostyly. Pp.179-193. In: S.C.H. Barrett (ed.). Evolution and function of heterostyly. Springer-Verlag, Berlin.
Machado, I.C. \& Loiola, M.I. 2000. Fly pollination and pollinator sharing in two synchronopatric species: Cordia multispicata (Boraginaceae) and Borreria alata (Rubiaceae). Revista Brasileira de Botânica 23: 305-311.

Melo, C.; Bento, E.C. \& Oliveira, P.E. 2003. Frugivory and dispersal of Faramea cyanea (Rubiaceae) in Cerrado woody plant formations. Brazilian Journal of Biology 63: 75-82.

Morellato, L.P.C.; Talora, D.C.; Takahasi, A.; Bencke, C.C.; Romera, E.C. \& Zipparro, V.B. 2000. Phenology of Atlantic rain forest trees: a comparative study. Biotropica 32: 811-823.

Newstrom, L.E.; Frankie, W.G. \& Baker, H.G. 1994. A new classification for plant phenology based on flowering patterns in lowland tropical rain forest trees at La Selva, Costa Rica. Biotropica 26: 141-159.

Opler, P.A.; Frankie, G.W. \& Baker, H.G. 1980. Comparative phenologycal studies of treelet and shrubs species in tropical wet and dry forest in the lowlands of Costa Rica. Journal of Ecology 68: 167-188.

Ornduff, R. 1970. Incompatibility and the pollen economy of Jepsonia parryi. American Journal of Botany 57: 1036-1044.

Ortiz, P.L.; Arisma, M. \& Tavalera, S. 2000. Pollination and breeding systems of Putoria calabrica (Rubiaceae), a Mediterranean dwarf shrub. Plant Biology 2: 325-330.

Passos, L. \& Sazima, M. 1995. Reproductive biology of the distylous Manettia luteo-rubra (Rubiaceae). Botanica Acta 108: 309-313.

Poulin, B.; Wright, S.J.; Lefebvre, G. \& Calderón, O. 1999. Interspecific synchrony and asynchrony in the fruiting phenologies of congeneric bird-dispersed plants in Panama. Journal of Tropical Ecology 15: 213-227.

Ramirez, N. \& Brito, Y. 1992. Pollination biology in a palm swamp community in the Venezuelan Central Plains. Botanical Journal of the Linnean Society 110: 277-302.

Ree, R.H. 1997. Pollen flow, fecundity and the adaptive significance of heterostyly in Palicourea padifolia (Rubiaceae). Biotropica 29: 298-308.

Richards, A.J. 1986. Plant breeding systems. London, Allen \& Unwin.

Riveros, G.M.; Barria, O.R. \& Humanã, A.M. 1995. Selfcompatibility in distylous Hedyotis salzmannii (Rubiaceae). Plant Systematics and Evolution 194: $1-8$.

San Martin-Gajardo, I. \& Morellato, L.P. 2003. Fenologia de Rubiaceae do sub-bosque em floresta Atlântica no sudeste do Brasil. Revista Brasileira de Botânica 26: 299-309.

Sazima, M.; Buzato, S. \& Sazima, I. 1996. An assemblage of hummingbird-pollinated flowers in a montane forest in southeastern Brazil. Botanica Acta 109: 149-160.

Stiles, F.G. 1975. Ecology, flowering phenology and hummingbird pollination of some Costa Rican Heliconia species. Ecology 56: 285-301.

Stone, J.L. 1996. Components of pollination effectiveness in Psychotria suerrensis, a tropical distylous shrub. Oecologia 107: 504-512. 
Tanner, E. 1982. Breeding systems in a tropical forest in Jamaica Biological Journal of the Linnean Society 18: 263-278.

Taylor, C.M. 1997. Conspectus of the genus Palicourea (Rubiaceae: Psychotriae) with the description of some new species from Ecuador and Colombia. Annals of the Missouri Botanical Garden 84: 224-262.

Weller, S.G. 1980. Pollen flow and fecundity in the population of Lithospermum carolinense. American Journal of Botany 67: 1334-1341.
Wiens, D.; Calvin, C.L.; Wilson, C.A.; Davern, C.I.; Frank, D. \& Seavey, S.R. 1987. Reproductive success, spontaneous embryo abortion, and genetic load in flowering plants. Oecologia 71: 501-509.

Wolff, D.; Braun, M. \& Liede, S. 2003. Nocturnal versus diurnal pollination success in Isertia laevis (Rubiaceae): A sphingophilous plant visited by hummingbirds. Plant Biology 5: 71-78. 